\title{
Substitution behaviors among people who gamble during COVID-19 precipitated casino closures
}

\author{
Silas Xuereb \\ Department of Psychology, Carleton University \\ Hyoun S. Kim \\ Department of Psychology, Ryerson University \\ Luke Clark
}

Centre for Gambling Research at UBC, and Department of Psychology, University of British Columbia

Michael J. A. Wohl*

Department of Psychology, Carleton University

This is an Author Accepted Manuscript. This paper is not the copy of record and may not exactly replicate the final, authoritative version of the article. Please do not copy or cite without authors' permission. The final article is published as: Xuereb S, Kim HS, Clark L, Wohl MJA. Substitution behaviors among people who gamble during COVID-19 precipitated casino closures. International Gambling Studies 2021, doi:

10.1080/14459795.2021.1903062.

Address for Correspondence: Michael J. A. Wohl, michael.wohl@ carleton.ca, 613-5202600 x2908, Department of Psychology, Carleton University. 1125 Colonel By Drive, K1S 5B6, Ottawa, ON, Canada. 
Funding. LC holds a Discovery Award from the Natural Sciences and Engineering Research Council (Canada) (RGPIN-2017-04069) and is Director of the Centre for Gambling Research at UBC. MW holds a Large Grant from the International Center for Responsible Gaming.

Declaration of interests. SX has received academic fees from Gambling Research Exchange Ontario. HSK has received funding and scholarships from the Alberta Gambling Research Institute and has received academic fees from Gambling Research Exchange Ontario. LC is the Director of the Centre for Gambling Research at UBC, which is supported by funding from the Province of British Columbia and the British Columbia Lottery Corporation (BCLC), a Canadian Crown Corporation. The Province of BC government and the BCLC had no role in the design, analysis, or interpretation of the study, and impose no constraints on publishing. LC has received a speaker/travel honorarium from the National Association for Gambling Studies (Australia) and the National Center for Responsible Gaming (US), and has received fees for academic services from the National Center for Responsible Gaming (US), GambleAware (UK), and Gambling Research Exchange Ontario (Canada). He has not received any further direct or indirect payments from the gambling industry or groups substantially funded by gambling. He has received royalties from Cambridge Cognition Ltd. relating to neurocognitive testing. MW has received research funding from Alberta Gambling Research Institute (Canada), British Columbia Lottery Corporation (Canada), Carleton University (Canada), Gambling Research Exchange (Canada), Manitoba Gambling Research Program (Canada), International Center for Responsible Gaming (US), Ontario Lottery and Gaming (Canada), and Ontario Ministry of Health and Long-Term Care (Canada). MW has received speaker/travel honorarium from Alberta Liquor Gaming Commission (Canada), National Association for Gambling Studies (Australia), the International Center for Responsible Gaming (US), and Massachusetts Council on Compulsive Gambling (US). He has received fees for academic services from Atlantic Lottery and Gaming Corporation 
(Canada), Gambling Research Exchange (Canada), International Center for Responsible Gaming (US), New South Wales Government (Australia), Nova Scotia Gaming Corporation (Canada), Manitoba Gambling Research Program (Canada), Massachusetts Gambling Commission (US), and Ontario Lottery and Gaming (Canada). MW has also received consulting fees from Alberta Liquor Gaming Commission (Canada), Atlantic Lottery and Gaming Corporation (Canada), British Columbia Lottery Corporation (Canada), GamRes (Canada), Massachusetts Gaming Commission (US), Nova Scotia Gaming Corporation (Canada), and Ontario Lottery and Gaming (Canada). 


\begin{abstract}
The COVID-19 pandemic triggered the closure of licensed casinos throughout the United States of America in March and April 2020. This study sought to examine how Americans who gamble responded to the COVID-19 lockdown, including migration to online gambling, and changes in substance use and use of other technologies. On April 9, 2020, we recruited an online sample of 424 Americans who gambled in the last three months via Amazon's Mechanical Turk. Self-reported changes in online gambling and other addictive behaviors since the onset of COVID-19 and problem gambling severity were measured. Overall, online gambling decreased following the onset of COVID-19 casino closures, while alcohol, tobacco, and cannabis use increased. Among respondents who reported no online gambling involvement prior to COVID-19, $15 \%$ reported migrating to online gambling. These migrators had higher levels of problem gambling and lower income than respondents who had never gambled online. The response to COVID-19 is heterogeneous: the majority of people who gamble reported reducing their online gambling but increased their substance use. A minority of people who gamble substituted casino gambling with online gambling. Because these individuals are characterized by problem gambling symptoms and lower income, they may be considered a vulnerable group.
\end{abstract}

Key words: Gambling; COVID-19; substitution; addiction; substance use 


\section{Introduction}

In late March 2020, mounting concern over the COVID-19 pandemic triggered an unprecedented event in the American gambling landscape: the mass closure of casino venues. For several months, Americans who gamble experienced an unexpected and dramatic contraction in their access to gambling. One avenue for gambling remained notably open: online gambling. Although the prevalence of online gambling remains fairly low (Kairouz \& Nadeau, 2014), technological developments in mobile access have resulted in a rapid expansion of this form of gambling (Wardle et al., 2019).

The term substitution refers to the migration of activities (i.e., switching one substance for another) when access to a preferred substance is blocked (Allsop et al., 2014; Lucas et al., 2013). Despite the substantial literature on substitution among people who use substances, a paucity of empirical attention has been directed at people who gamble when their access is blocked, however, preliminary evidence suggests that substitution does occur among people who gamble (Kim, 2020). This is perhaps unsurprising given that at the heart of substitution is the search for reinforcements that are similar to the addictive behavior that has been blocked (Kazdin, 1982). For example, a person who gambles to cope with negative life events but who no longer has access to gambling may increase their use of other addictive substances (e.g., alcohol) or behaviors (e.g., online gambling) as a replacement route of escape. At present, the literature has been relatively silent on possible substitution within forms of gambling (e.g., from land-based to online gambling). This knowledge gap is striking in light of the concerns that have been expressed about the possibility of migration to online gambling due to the COVID-19 precipitated closure of land-based gambling venues.

It is likely that the response among people who gamble to the casino closure may have been shaped by a number of further facets of the pandemic. Physical distancing measures may lead to boredom and social isolation, which can be potent triggers of gambling 
in at least some individuals (Mercer \& Eastwood, 2010). In addition, the pandemic precipitated an economic crisis at both the country and individual level. Although the relation between GDP and gambling is complex (Baumöhl \& Výrostová, 2017; Olason et al., 2017), gambling participation increased following the Icelandic banking collapse (primarily in lottery products), and these effects may be stronger among individuals who were financially affected (Economou et al., 2019; Wohl et al., 2014). Herein, we tested the idea that the COVID-19-related closure of land-based casinos, combined with social isolation and economic crisis, may have resulted in substituting land-based casino gambling for online gambling among people who gamble.

In addition to substituting to online gambling, it is possible that people who gamble at land-based casinos may increase their engagement in other addictive behaviors (Kim, 2020). There is accumulating evidence that alcohol sales increased after physical distancing measures were introduced (Rehm et al., 2020), and there is preliminary evidence for similar increases in cannabis use (George-Cosh, 2020). It is also possible that in addition to migrating to online gambling, people who gamble at land-based casinos may substitute with other substances during the current pandemic as a way to alleviate negative emotional states (Bilocati et al., 2016). Understanding whether a pattern of increased online gambling along with increases in substance use is taking place has important implications given that simultaneous use of gambling and substances may increase gambling harms (Punia et al., in press; Sagoe et al., 2017).

When access to gambling is constricted, people who gamble may also increase their use of other potentially addictive technologies (e.g., video games, pornography), which often co-occur with disordered gambling (Potenza et al., 2018). Indeed, Kim (2020) found that people who recovered from gambling were more likely to report substituting to behavioral addictions, including addictive technologies, than to psychoactive substances. We had an $a$ 
priori interest in social casino games. Social casino games are a specific genre of video games that simulates gambling using virtual credits instead of real money. Social casino games have been found to increase real money gambling when people use them to improve their gambling skills, but may also decrease real money gambling when used to downregulate craving to gamble (Hollingshead et al., 2016; Kim et al., 2015). Thus, it is possible that during COVID-19 (a time when opportunities for in-person gambling are reduced) an increase in social casino gaming may be related to readiness to change among people who gamble at land-based casinos.

The goal of the present study was to examine patterns of substitution in land-based gambling in the United States following the COVID-19 precipitated casino closures, with particular attention to their migration to online gambling. It is important to note that despite the fact that online gambling is illegal in some U.S. states, many states now permit online casinos, online poker and/or online sports betting, and studies have shown that tens of millions of Americans gamble online each year (e.g., Cooper, 2011; Sloan, 2020). Additionally, a systematic review by Nagelhout and colleagues (2017) showed that illegal drug use increases during an economic downturn. As such, substitution behavior is ripe for study in light of COVID-19 precipitated casino closures and the shuttering of the economy to reduce the spread of COVID-19. To this end, we examined whether there were changes in online gambling following the closure of land-based casinos in the United States due to COVID-19. We also examined changes in use of legal as well as illegal substances and other putative behavioral addictions during COVID-19. Open-ended questions assessed people's reasons (e.g., boredom) for reported changes. Lastly, we compared demographic and gambling characteristics in those who migrated to online gambling compared to those who did not.

\section{Methods}




\section{Procedure}

We pre-registered our primary hypothesis, sample size $(N=500)$ and exclusion criteria on AsPredicted (https://aspredicted.org/vu6mf.pdf). Our analysis deviated from our preregistration in that we used a two-tailed t-test instead of a one-tailed test, because the mean change in online gambling had the opposite sign to that expected.

Given the novel nature of this research, we did not conduct an a priori power analysis. Instead, after the data was collected, we conducted a sensitivity analysis using G*Power 3.1.9.7. This analysis revealed that our sample of 221 individuals with online gambling experience had $80 \%$ power to detect an effect size of $d=0.172$ at $\mathrm{a}=0.05$. In other words, our sample size was sufficient to detect small effects.

We hosted a survey on Amazon's Mechanical Turk (MTurk) on April 9 ${ }^{\text {th }}, 2020$ that was described as seeking casino gamblers for a study about behavioral responses to the closure of land-based casinos due to COVID-19. After providing informed consent, respondent s completed a Captcha to prevent bots from completing the survey.

We obtained ethics approval for this research from the Research Ethics Board associated with the first author's institution.

\section{Participants}

MTurk workers were eligible to participate if they were American citizens, at least 18 years of age, and had gambled at a land-based casino within the past three months. We restricted the time-frame to last three months to reduce potential bias stemming from participants' poor recall about their gambling behaviour (see Wohl et al., 2017). Of the 639 people who started the survey, three did not provide consent to participate, 58 did not pass our eligibility screening, and 67 did not complete the survey, leaving 506 complete surveys. These participants were compensated with $\$ 0.75$ (median completion time was seven minutes and 42 seconds). To address concerns with MTurk data integrity, and as outlined in our pre- 
registration, we removed 31 participants who passed the eligibility criteria but later indicated that they had not gambled in the past three months, 10 participants who left open-ended questions blank and 41 who provided incoherent open-ended responses or only provided extreme responses (which can be indicative of bots and inattentive responding). Our final sample consisted of 424 people who ranged in age from 19-82 $(M=37.93, S D=12.33)$ and $36.1 \%$ were female. Ninety-five percent of participants confirmed that casinos had closed in their area.

\section{Materials}

Online gambling. Participants were asked whether they had ever engaged in online gambling prior to the closure of land-based casinos. If they had not, they were asked whether they had started online gambling since the closures. Measures related to online gambling were assessed if participants responded affirmatively to either of these questions. These measures included whether their online gambling had increased, stayed the same, or decreased since the casino closures (coded as 1, 0 and -1, respectively), and the magnitude of change in their online gambling on a scale from 0 ('Not at all') to 3 ('A lot'). Additional measures regarding limit setting were assessed but are not reported here.

Changes in other behaviors due to COVID-19. Changes in other potentially addictive behaviors, including alcohol use, tobacco use, cannabis use, video gaming, social casino gaming, and pornography use, were assessed using similar items as those presented for changes in online gambling. Participants were asked whether each behavior had increased, stayed the same, decreased, or stayed the same because they had never used it, and the magnitude of the change in their behavior.

An open-ended question asked participants to explain why their behaviors had increased ('Please tell us why you increased the use of substances or other behaviors') or decreased ('Please tell us why you decreased the use of substances or other behaviors'). 
Open-ended responses were read by the first author and coded according to participants' expressed motivation to increase their substance and behavioral addictions.

Readiness to change. The Readiness to Change ladder (Biener \& Abrams, 1991) was used to assess participants' preparedness to change their gambling behavior on a scale from 0 ('No thought of changing') to 10 ('Taking action to change (e.g., cutting down, enrolling in a program)').

Problem gambling. Problem gambling severity was measured using the Problem Gambling Severity Index (PGSI; Ferris \& Wynne, 2001) ( $M=7.83, S D=7.05 ; \mathrm{a}=.94)$. The PGSI contains nine total items and are anchored on a scale at 0 ('Never') and 3 ('Almost always'). As such, participant's scores ranged from 0 to a maximum of 27 . We kept the scores as a continuous variable in our analyses.

Demographics. Participants answered demographic questions to assess their age, gender, marital status, ethnicity, education, job status, and household income.

\section{Data Preparation / Analysis}

Analyses were carried out using SPSS 25. Our primary dependent variable was change in online gambling. This was computed as the product of the direction of change in online gambling and the magnitude of change in online gambling. Other behavior change variables were computed in the same fashion. Individuals who had never used a substance or technology were treated as missing and excluded analysis by analysis.

Non-parametric tests were used because the dependent variables were not normally distributed according to Shapiro-Wilk tests. Wilcoxon signed rank tests were used to assess whether each behavior had significantly changed since the closure of land-based casinos, with $r=Z / \sqrt{ } n$ used as a measure of effect size (Tomczak \& Tomczak, 2014). Kruskal-Wallis tests were used to compare migrators to online gambling, people with prior online gambling involvement and people who gambled exclusively at land-based venues , on demographics, 
problem gambling severity and behavioral change scores with partial $\eta^{2}$ calculated as suggested by Murphy and colleagues (2014) used as a measure of effect size. We have not corrected for familywise error rate because, aside from the test of change in online gambling, the tests were purely exploratory. Parametric tests can also be found in the supplemental files on OSF.

\section{Results}

Table 1 reports demographic characteristics of the respondents. Our sample is slightly younger and significantly more male than the general United States population (U. S. Census Bureau, 2020a). Individuals with higher education levels and those in the middle of the income distribution are also overrepresented (U. S. Census Bureau, 2020b).

[Table 1]

Although in the subsequent analyses we used the PGSI as a continuous measure, a participant's total PGSI score can be used to place them into one of four categories: nonproblem (score of 0 ), low-risk (score of 1 or 2), moderate-risk (score of 3 to 7), and problem gambling (score of 8 to 27). For descriptive purposes, in the current sample, $13 \%(n=58)$ were not at risk for problem gambling, $21 \%(n=89)$ were at low-risk for problem gambling, $21.9 \%(n=93)$ were at moderate risk for problem gambling and $43.4 \%(n=184)$ were experiencing problem gambling. This problem gambling rate is much higher than that found in the general population. However, it is consistent with other research on problem gambling that has used MTurk samples of people who gamble (Pickering \& Blaszczynski, 2021) and may be an indicator of non-representative sampling.

\section{Activities of people who gamble during COVID-19}

Spearman correlations between variables are reported in Table 2. As predicted, an increase in online gambling was positively associated with PGSI, $\rho_{219}=0.210, p=0.002$. Furthermore, online gambling change was positively associated with alcohol use, $\rho_{159}=0.169$, 
$p=0.032$, tobacco use, $\rho_{127}=0.274, p=0.002$, pornography use, $\rho_{151}=0.228, p=0.005$, and social casino gaming, $\rho_{181}=0.342, p<0.001$. Contrary to our hypothesis, an increase in online gambling was positively (not negatively) associated with readiness to change, $\rho_{219}=0.139$, $p=0.039$.

[Table 2]

Behavior change. Using Wilcoxon signed-rank tests, we assessed whether substance use and other addictive behaviors increased since the closure of land-based casinos (see Table 3). Contrary to expectations, participants who gambled online reported a significant decrease in online gambling since the casino closure, $Z=-3.06, p=0.002, r=0.21$. However, as predicted among those who had ever used each substance, there were significant increases in alcohol, tobacco, and cannabis use, $p$ s <.01. Likewise, there were significant increases in technology use, including video games, pornography use, and social casino gaming, $p \mathrm{~s}<.001$.

[Table 3]

Motivations to increase behaviors. $56.9 \%$ of respondents indicated that increases in potentially addictive substances and behaviors were due to boredom or an increase in free time, $11.2 \%$ indicated that it was due to increased stress or anxiety, and $1.2 \%$ indicated it was to fill the void left by the lack of land-based gambling. The remaining respondents either did not increase any behaviors or did not provide a clear motivation.

\section{Online gambling: Between group comparisons}

Inspection of the data revealed three subgroups of people who gamble: 1) those who migrated to online gambling as a result of the casino closures $(n=35 ; 8 \%$ of full sample; $15 \%$ of those with no prior online gambling involvement), 2) those who gambled online prior to the COVID-19 casino closures $(n=186 ; 44 \%)$, and 3$)$ those who neither gambled online prior nor during the casino closures $(n=203 ; 48 \%)$.

[Table 4] 
Kruskal-Wallis tests were used to compare these three groups on demographic characteristics and behavior changes (Table 4). There were significant differences between groups on PGSI, $\chi^{2}=74.32, p<0.001$, partial $\eta^{2}=0.159$. People who had never gambled online had significantly lower PGSI (Mean rank=159.16) than migrators (Mean rank=267.03), 95\% CI for difference in mean ranks $=[64.04,151.70], p<0.001$, and those with prior online gambling involvement (Mean rank=260.46), 95\% CI for difference in mean ranks=[77.00, 125.60], $p<0.001$. Household income also differed significantly across groups, $\chi^{2}=10.61$, $p=0.005$, partial $\eta^{2}=0.025$, with migrators (Mean rank=161.46) earning significantly less income than those who had never gambled online (Mean rank=228.71), 95\% CI for difference in mean ranks $=[-110.84,-23.66], p=0.007$. Group differences in age were also present, $\chi^{2}=13.54, p=0.001$, partial $\eta^{2}=0.032$ : people who exclusively gambled at land-based venues (Mean rank=234.56) were significantly older than people with prior online gambling involvement (Mean rank=192.90) 95\% CI for difference in mean ranks=[-66.00, -17.32], $p=0.002$. There were no significant differences between groups in changes in alcohol use, tobacco use, or cannabis use. Group differences existed in changes in video gaming, $\chi^{2}=7.67$, $p=0.022$, partial $\eta^{2}=0.025$, pornography use, $\chi^{2}=8.28, p=0.016$, partial $\eta^{2}=0.025$, and changes in social casino gaming, $\chi^{2}=12.19, p=0.020$, partial $\eta^{2}=0.047$. Pornography use increased more for migrators (Mean rank=159.00) than people who exclusively gambled at land-based venues (Mean rank=117.33), 95\% CI for difference in mean ranks=[10.97, 72.37] $p=0.024$. Video gaming increased more for people with prior online gambling involvement (Mean rank=163.7) than people who exclusively gambled at land-based venues (Mean rank $=135.20), 95 \% \mathrm{CI}$ for difference in mean ranks $=[8.29,48.71], p=0.017$. Social casino gaming increased more for migrators (Mean rank=170.22) than both people with prior online gambling involvement (Mean rank=134.02), 95\% CI for difference in mean ranks=[6.88, 
65.52], $p=0.0476$, and people who exclusively gambled at land-based venues $(M=115.16)$, 95\% CI for difference in mean ranks $=[23.76,86.37] p=0.002$.

\section{Discussion}

Results from our assessment of people who gambled at land-based casinos prior to COVID-19 show that these individuals decreased their online gambling during the pandemic lockdown. This is consistent with Turner (2020) who found that gambling-related helpline calls decreased during COVID-19 casino closures. At the same time, a portion of the sample displayed substitution to online gambling. Specifically, $15 \%$ of our participants with no prior online gambling involvement reported starting to gamble online as a result of casino closures. This is in line with Price (2020) who found 54\% of people who gamble in Ontario reported gambling online during the pandemic while only $23 \%$ reported gambling online regularly prior to the pandemic.

Of concern, in the current study, those who migrated also had elevated disordered gambling symptomatology and had lower income than people who exclusively gambled at land-based venues. These results are in line with previous studies that found that although only a minority of people will engage in addiction substitution, those who do are likely to be vulnerable to problematic engagement in addictions (Kim, 2020). Given that people with problem gambling account for a disproportionate amount of gambling revenue, that migrators were higher in disordered gambling symptomatology may explain the elevated revenues of online gambling operators in the United States observed during the pandemic (American Gaming Association, 2020).

Additionally, these results support preliminary research in Sweden that suggested the closure of land-based gambling venues may trigger a subset of vulnerable individuals to switch to online gambling (Håkansson, 2020). In this light, it is prudent for gambling operators to monitor for spikes in new customers, and whether these people are gambling 
excessively in response to fluctuations in land-based gambling opportunities with the ongoing pandemic. If so, gambling operators and regulators may consider a variety of actions as part of a public health response, and in anticipation of possible later waves of COVID-19 infections or a future pandemic, including a more cautious approach to marketing, imposing mandatory loss limits, and increased provision of responsible gambling tools (Gainsbury et al., 2018).

Interestingly, aside from the migrators, online gambling decreased on average since the closure of land-based casinos due to COVID-19. Given the suspension of most major sports leagues during the early stages of the pandemic, this phenomenon may be partially driven by a fall in sports betting (Auer et al., 2020). At the same time, overall use of addictive substances (e.g., alcohol, cannabis) and engagement with addictive technologies (e.g., social casino gaming) increased. Although we lack control data on population-level changes in these activities, these results may suggest a broader substitution effect among people who gamble at land-based venue s during COVID-19. Specifically, there may be compensatory increases in other activities when one addictive behavior is no longer available. Similar to addiction substitution during recovery, those who substitute land-based gambling with other addictive substances or behaviors during COVID-19 are at risk of ultimately developing new dependencies on those substances and behaviors (Kim, 2020). Unfortunately, simultaneous use of substances whilst (online) gambling is associated with excessive gambling (Papineau et al., 2018). Thus, although online gambling decreased overall, migration to online gambling and the increased use of other addictive substances may lead to increased prevalence of disordered gambling and other substance use disorders as a result of COVID-19.

More than half of the participants noted negative affect (e.g., boredom, anxiety) as their primary reason for their increased use of other addictive substances and behaviors. Although this does not confirm that addiction substitution is the cause of these increases in 
use of other addictive substances and behaviors, previous research found that addiction substitution often occurs outside of conscious awareness and that negative affect was one of the most common reasons people reported for engaging in addiction substitution (Kim, 2020). Specifically, participants were likely searching for a new means to manage distress, now that their pre-COVID means (land-based gambling) were not available. This supports the notion that people will engage in addiction substitution when the new addiction provides similar reinforcements to the primary addiction (Adler, 1966; Kim, 2020). Unfortunately, physical distancing measures and economic crisis are likely to increase the presence of mental health concerns and at the same time limit healthy alternative coping skills to manage distress (e.g., social supports). In this light, it may be prudent for online treatments and supports to acknowledge and provide strategies consistent with restrictions placed by COVID-19.

We note that participants also reported increased use of social casino gaming following casino closure. Although concerns have been raised that social casino games may increase future gambling (Kim et al., 2015), it is important to acknowledge that social casino gaming may have prophylactic effects in people who gamble. As reported by Hollingshead and colleagues, people who gamble may turn to these free-to-play casino-style games as a means of regulating their craving to gamble with no associated financial costs (Hollingshead et al., 2016). Unfortunately, we did not assess why some people who gamble turned to social casino games. However, it is likely that some participants yielded benefits from playing social casino games (i.e., a reduction in gambling). Although the similarities between gambling and social casino games have generally been considered to be problematic, in the context of COVID-19, it may provide an alternate and less harmful activity to both landbased and online gambling.

To our knowledge, the current study is the first to directly test the effect of the casino closure in the United States on online gambling and substitution to substances and other (non- 
gambling) technologies among people who gamble at land-based venues. We conducted this study, in part, because of media speculation that alcohol, cannabis, video gaming, and pornography use were increasing after physical isolation measures were put in place. Examining whether people are transitioning to online gambling and other addictive behaviors during COVID-19 is of importance given the high accessibility of online gambling (and thus the potential for excessive spending) and increased use of addictions in the context of physical distancing and economic burden.

\section{Limitations}

Some limitations of the current research should be noted. First, due to the crosssectional design, the cause of migration to online gambling and changes in other addictions is undetermined. Although we established that people who gamble have increased their substance use and some have migrated to online gambling in the past couple months, we cannot attribute these changes directly to the closure of land-based casinos. Furthermore, we did not compare our sample to a control group of people who do not gamble and thus future studies are needed to replicate our findings. Second, longitudinal studies are needed to assess the longer-term influences that COVID-19 has on people who gamble's behavior. Third, the results presented are based on subjective reports of behavior and behavior change. However, given the recency and salience of COVID-19, variance from objective measures (e.g., casino player account data) is likely minimal. Fourth, our sample consisted of MTurk participants and thus is not a representative sample of people who gamble at land-based venues. The rates of problem gambling on the PGSI were considerably higher in our sample than populationlevel prevalence, likely as a result of selection bias. The high rate of problem gambling was likely due to the framing of the study, which specifically recruited people who gamble. Recent research suggests that framing a study about gambling is associated with higher rates of problem gambling, which may have biased our sample (Angus et al., 2021). Nevertheless, 
crowdsourcing platforms have shown utility for recruiting addiction populations including people who engage in gambling (Kim \& Hodgins, 2017; 2020). Research with a representative sample of people who gamble at land-based venues and objective data (e.g., from account-based gambling) would inform both short- and long-term strategies to contend with problems experienced by people who gamble as a result of the changing access to gambling following COVID-19. Finally, collecting data on state of residency would be useful to assess whether substitution that involves online gambling is greater in jurisdictions that have legalized online gambling compared to jurisdictions in which online gambling is illegal.

\section{Conclusion}

The ongoing COVID-19 pandemic is unprecedented in its impact on societal disruption. Importantly for the present research, it has been hypothesized that the closure of land-based casinos may have precipitated migration to online gambling (see Marsden et al., 2020). In line with other recent research (Price, 2020), we found empirical evidence to support this supposition. Additionally, we also demonstrated that the migration to online gambling should not be the only concern among people who gamble at land-based venues. Indeed, we found significant increases in other substance and behavioral addictions. Physical distancing measures and economic uncertainty arising from COVID-19 may have an array of negative effects on people's mental health and well-being. The current study adds to the growing body of research on these effects by demonstrating that the closure of casinos may result in addiction substitution and a potential increase in disordered gambling among those who migrate to online gambling. Public health officials and treatment providers should direct attention towards migrators to online gambling and anticipate changes in other addictive behaviors when access to land-based gambling changes. 
Data availability statement. All data and code used in this research can be found at https://osf.io/py45w/?view_only=513a3b58d0884e1c87c5558b2212c4ec 


\section{References}

Adler, J. (1966). Gambling, Drugs, and Alcohol: A Note on Functional Equivalents. Issues in Criminology, 2, 111.

Allsop, D. J., Dunlop, A. J., Sadler, C., Rivas, G. R., McGregor, I. S., \& Copeland, J. (2014). Changes in cigarette and alcohol use during cannabis abstinence. Drug and Alcohol Dependence, 138, 54-60. https://doi.org/10.1016/j.drugalcdep.2014.01.022

American Gaming Association. (2020, August). 2020 Q2 Commercial Gaming Revenue Tracker. https://www.americangaming.org/wp-content/uploads/2020/08/2020-Q2Commercial-Gaming-Revenue-Tracker.pdf

Angus, D. J., Pickering, D., Keen, B., \& Blaszczynski, A. (2021). Study framing influences crowdsourced rates of problem gambling and alcohol use disorder. Psychology of Addictive Behaviors. doi: 10.1037/adb0000687.

Auer, M., Malischnig, D., \& Griffiths, M. D. (2020). Gambling Before and During the COVID-19 Pandemic Among European Regular Sports Bettors: An Empirical Study Using Behavioral Tracking Data. International Journal of Mental Health and Addiction. https://doi.org/10.1007/s11469-020-00327-8

Baumöhl, E., \& Výrostová, E. (2017). Do people gamble more in good times? Evidence from 27 European countries. Applied Economics Letters, 24(18), 1311-1314. https://doi.org/10.1080/13504851.2016.1273484

Biener, L., \& Abrams, D. B. (1991). The contemplation ladder: Validation of a measure of readiness to consider smoking cessation. Health Psychology, 10(5), 360-365.

Bilocati, R., Pissani, S., \& Mancini, G. (2016). “I cannot stand the boredom.” Binge drinking expectancies in adolescence. Addictive Behaviors Reports, 3, 70-76. http://dx.doi.org/10.1016/j.abrep.2016.05.001

Cooper, A. F. (2011). Internet gambling offshore: Caribbean struggles over casino 
capitalism. Springer.

Economou, M., Souliotis, K., Malliori, M., Peppou, L. E., Kontoangelos, K., Lazaratou, H., Anagnostopoulos, D., Golna, C., Dimitriadis, G., Papadimitriou, G., \& Papageorgiou, C. (2019). Problem Gambling in Greece: Prevalence and Risk Factors During the Financial Crisis. Journal of Gambling Studies, 35(4), 1193-1210. https://doi.org/10.1007/s10899-019-09843-2

Ferris, J. A., \& Wynne, H. J. (2001). The Candian problem gambling index. Canadian Centre on Substance Abuse.

Gainsbury, S. M., Abarbanel, B. L. L., Philander, K. S., \& Butler, J. V. (2018). Strategies to customize responsible gambling messages: A review and focus group study. $B M C$ Public Health, 18(1), 1381. https://doi.org/10.1186/s12889-018-6281-0

George-Cosh, D. (2020, April 16). Ontario online pot purchases jump 600\% amid COVID-19 pandemic, data shows. BNN Bloomberg. https://www.bnnbloomberg.ca/ontarioonline-pot-purchases-jump-600-amid-covid-19-pandemic-data-shows-1.1422369

Håkansson, A. (2020). Changes in Gambling Behavior during the COVID-19 Pandemic-A Web Survey Study in Sweden. International Journal of Environmental Research and Public Health, 17(11), 4013. https://doi.org/10.3390/ijerph17114013

Hollingshead, S. J., Kim, H. S., Wohl, M. J. A., \& Derevensky, J. L. (2016). The Social Casino Gaming-Gambling Link: Motivation for Playing Social Casino Games Determines Whether Self-Reported Gambling Increases or Decreases Among Disordered Gamblers. Journal of Gambling Issues, 33, 52. https://doi.org/10.4309/jgi.2016.33.4

Kairouz, S., \& Nadeau, L. (2014). Portrait du jeu au Québec: Prévalence, incidence et trajectoires sur quatre ans (p. 64). Université Concordia.

Kazdin, A. E. (1982). Symptom substitution, generalization, and response covariation: 
Implications for psychotherapy outcome. Psychological Bulletin, 91(2), 349-365.

Kim, H. S. (2020). Addiction Substitution and Concurrent Recovery in Gambling Disorder: Evidence from Multiple Studies [University of Calgary]. https://prism.ucalgary.ca/handle/1880/112406

Kim, H. S., \& Hodgins, D. C. (2017). Reliability and validity of data obtained from alcohol, cannabis, and gambling populations on Amazon's Mechanical Turk. Psychology of Addictive Behaviors, 31(1), 85-94. https://doi.org/10.1037/adb0000219

Kim, H. S., \& Hodgins, D. C. (2020). Are you for real? Maximizing participant eligibility on Amazon's Mechanical Turk. Addiction, 115(10), 1969-1971. https://doi.org/10.1111/add.15065

Kim, H. S., Wohl, M. J. A., Salmon, M. M., Gupta, R., \& Derevensky, J. (2015). Do Social Casino Gamers Migrate to Online Gambling? An Assessment of Migration Rate and Potential Predictors. Journal of Gambling Studies, 31(4), 1819-1831. https://doi.org/10.1007/s10899-014-9511-0

Lucas, P., Reiman, A., Earleywine, M., McGowan, S. K., Oleson, M., Coward, M. P., \& Thomas, B. (2013). Cannabis as a substitute for alcohol and other drugs: A dispensary-based survey of substitution effect in Canadian medical cannabis patients. Addiction Research \& Theory, 21(5), 435-442. https://doi.org/10.3109/16066359.2012.733465

Marsden, J., Darke, S., Hall, W., Hickman, M., Holmes, J., Humphreys, K., Neale, J., Tucker, J., \& West, R. (2020). Mitigating and learning from the impact of COVID-19 infection on addictive disorders. Addiction, 115(6), 1007-1010. https://doi.org/10.1111/add.15080

Mercer, K. B., \& Eastwood, J. D. (2010). Is boredom associated with problem gambling behaviour? It depends on what you mean by 'boredom.' International Gambling 
Studies, 10(1), 91-104. https://doi.org/10.1080/14459791003754414

Murphy, K. R., Myors, B., \& Wolach, A. (2014). Statistical power analysis: A simple and general model for traditional and modern hypothesis tests. Routledge.

Nagelhout, G. E., Hummel, K., de Goeij, M. C. M., de Vries, H., Kaner, E., \& Lemmens, P. (2017). How economic recessions and unemployment affect illegal drug use: A systematic realist literature review. International Journal of Drug Policy, 44, 69-83. https://doi.org/10.1016/j.drugpo.2017.03.013

Olason, D. T., Hayer, T., Meyer, G., \& Brosowski, T. (2017). Economic Recession Affects Gambling Participation But Not Problematic Gambling: Results from a PopulationBased Follow-up Study. Frontiers in Psychology, 8, 1247. https://doi.org/10.3389/fpsyg.2017.01247

Papineau, E., Lacroix, G., Sévigny, S., Biron, J.-F., Corneau-Tremblay, N., \& Lemétayer, F. (2018). Assessing the differential impacts of online, mixed, and offline gambling. International Gambling Studies, 18(1), 69-91. https://doi.org/10.1080/14459795.2017.1378362

Pickering, D., \& Blaszczynski, A. (2021). Paid online convenience samples in gambling studies: questionable data quality. International Gambling Studies. doi: $10.1080 / 14459795.2021 .1884735$

Potenza, M. N., Higuchi, S., \& Brand, M. (2018). Call for research into a wider range of behavioural addictions. Nature, 555(7694). https://doi.org/10.1038/d41586-01802568-Z

Price, A. (2020). Online Gambling in the Midst of COVID-19: A Nexus of Mental Health Concerns, Substance Use and Financial Stress. International Journal of Mental Health and Addiction. https://link.springer.com/article/10.1007/s11469-020-00366-1

Punia, K., deVillaer, M., Mackillop, J., \& Balodis, I. M. (in press). Understanding the overlap 
between cannabis use and gambling behavior: A systematic review of empirical findings and consideration of policy implications. Current Addiction Reports.

Rehm, J., Kilian, C., Ferreira-Borges, C., Jernigan, D., Monteiro, M., Parry, C. D. H., Sanchez, Z. M., \& Manthey, J. (2020). Alcohol use in times of the COVID 19: Implications for monitoring and policy. Drug and Alcohol Review, 39(4), 301-304. https://doi.org/10.1111/dar.13074

Sagoe, D., Mentzoni, R. A., Leino, T., Molde, H., Haga, S., Gjernes, M. F., Hanss, D., \& Pallesen, S. (2017). The effects of alcohol expectancy and intake on slot machine gambling behavior. Journal of Behavioral Addictions, 6(2), 203-211. https://doi.org/10.1556/2006.6.2017.031

Sloan, S. (2020). Putting Texas Back in Texas Hold 'Em. Sports Lawyers Journal, 27, 103136.

Tomczak, M., \& Tomczak, E. (2014). The need to report effect size estimates revisited. An overview of some recommended measures of effect size. 1,7 .

Turner, N. E. (2020). COVID-19 and Gambling in Ontario. Journal of Gambling Issues, 44(0), Article 0. https://doi.org/10.4309/jgi.2020.44.1

U. S. Census Bureau. (2020a). 2019 American Community Survey Table S0101. https://data.census.gov/cedsci/table?q=Age\%20and\%20Sex\&tid=ACSST1Y2019.S01 $01 \&$ hidePreview $=$ false

U. S. Census Bureau. (2020b). 2019 Current Population Survey Historical Income Tables. https://www.census.gov/data/tables/time-series/demo/income-poverty/historicalincome-households.html

Wardle, H., Reith, G., Langham, E., \& Rogers, R. D. (2019). Gambling and public health: We need policy action to prevent harm. BMJ, 365, 11807. https://doi.org/10.1136/bmj.11807 
Wohl, M. J. A., Branscombe, N. R., \& Lister, J. J. (2014). When the Going Gets Tough: Economic Threat Increases Financial Risk Taking in Games of Chance. Social Psychological and Personality Science, 5(2), 211-217. https://doi.org/10.1177/1948550613490964

Wohl, M. J. A., Davis, C. G., \& Hollingshead, S. J. (2017). How much have you won or lost? Personalized behavioral feedback about gambling expenditures regulates play. Computers in Human Behavior, 70, 437-445. https://doi.org/10.1016/j.chb.2017.01.025 
Table 1 Demographic characteristics of the sample

\begin{tabular}{lcc}
\hline Variable & $n$ & $\%$ \\
\hline Age & $37.9(12.3)$
\end{tabular}

Gender

Male

Female

Other

Education level

High school or less

Some post-secondary

Bachelor's degree

Graduate degree

Job status

Employed full-time

Employed part-time

Unemployed

Household income

Under $\$ 30,000$

$\$ 30,000$ - \$49,999

$\$ 50,000$ - $\$ 69,999$

$\$ 70,000$ - \$99,999

Over $\$ 100,000$

Marital status

Married/common-law

Single

Separated/divorced/widowed

Ethnicity

White

307

Black

Latin American

Other
50

94

270

153

1

63.7

36.1

.2

57

13.4

102

24.1

181

42.7

84

19.8

38

78.5

9.0

21

5.0

92

101

87

11.8

22.2

21.7

23.8

20.5

259

61.1

141

24

72.4

71

16.7

17

4.0

29

6.8

Note. Mean (SD) presented for age. Percentages may not add up to $100 \%$ due to rounding. 
Table 2 Correlations between key variables.

\begin{tabular}{|c|c|c|c|c|c|c|c|c|}
\hline & 1. & 2. & 3. & 4. & 5. & 6. & 7. & 8. \\
\hline $\begin{array}{l}\text { 1. Change in } \\
\text { online } \\
\text { gambling }\end{array}$ & & & & & & & & \\
\hline 2. PGSI & $\begin{array}{r}.210 \\
* *\end{array}$ & & & & & & & \\
\hline $\begin{array}{l}\text { 3. Readiness } \\
\text { to change }\end{array}$ & $\begin{array}{r}.139 \\
*\end{array}$ & $\begin{array}{r}.602 \\
* *\end{array}$ & & & & & & \\
\hline $\begin{array}{l}\text { 4. Change in } \\
\text { social casino } \\
\text { gaming }\end{array}$ & $\begin{array}{r}.342 \\
* *\end{array}$ & $\begin{array}{r}.247 \\
* *\end{array}$ & $\begin{array}{r}.129 \\
*\end{array}$ & & & & & \\
\hline $\begin{array}{l}\text { 5. Change in } \\
\text { alcohol use }\end{array}$ & $\begin{array}{r}.169 \\
*\end{array}$ & .085 & .023 & $\begin{array}{r}.150 \\
*\end{array}$ & & & & \\
\hline $\begin{array}{l}\text { 6. Change in } \\
\text { tobacco use }\end{array}$ & $\begin{array}{r}.274 \\
* *\end{array}$ & $\begin{array}{r}.163 \\
*\end{array}$ & .030 & $\begin{array}{r}.223 \\
* *\end{array}$ & $\begin{array}{r}.438 \\
* *\end{array}$ & & & \\
\hline $\begin{array}{l}\text { 7. Change in } \\
\text { cannabis use }\end{array}$ & .140 & .123 & .086 & $\begin{array}{r}.135 \\
*\end{array}$ & $\begin{array}{r}.354 \\
* *\end{array}$ & $\begin{array}{r}.405 \\
* *\end{array}$ & & \\
\hline $\begin{array}{l}\text { 8. Change in } \\
\text { video gaming }\end{array}$ & .072 & .104 & .025 & $\begin{array}{r}.240 \\
* *\end{array}$ & .072 & .080 & $\begin{array}{r}- \\
.016\end{array}$ & \\
\hline $\begin{array}{l}\text { 9. Change in } \\
\text { pornography } \\
\text { use }\end{array}$ & $\begin{array}{r}.228 \\
* *\end{array}$ & $\begin{array}{r}.261 \\
* *\end{array}$ & .101 & $\begin{array}{r}.301 \\
* *\end{array}$ & $\begin{array}{r}.172 \\
*\end{array}$ & .122 & $\begin{array}{r}.286 \\
* *\end{array}$ & $\begin{array}{r}.243 \\
* *\end{array}$ \\
\hline
\end{tabular}

Note. $* * p<0.01, * p<0.05$. Bivariate Spearman correlations presented. PGSI $=$ Problem

Gambling Severity Index. 
Table 3 Changes in substance and technology use among people who gamble since casino closures.

\begin{tabular}{lcccr}
\hline & Mean $(S D)$ & $P$-value & $Z$ & $r$ \\
\hline Change in online gambling & $-0.324(1.68)$ & 0.002 & -3.06 & 0.206 \\
Change in alcohol use & $0.327(1.31)$ & $<0.001$ & 4.03 & 0.229 \\
Change in tobacco use & $0.316(1.36)$ & 0.003 & 3.00 & 0.209 \\
Change in cannabis use & $0.247(1.27)$ & 0.009 & 2.62 & 0.196 \\
Change in video gaming & $1.223(1.34)$ & $<0.001$ & 10.99 & 0.635 \\
Change in pornography use & $0.473(1.31)$ & $<0.001$ & 5.45 & 0.339 \\
Change in social casino & $0.532(1.42)$ & $<0.001$ & 5.18 & 0.319 \\
gaming & & & & \\
\hline
\end{tabular}

Note. Each variable was measured on a scale from -3 (decreased a lot) to 3 (increased a lot). $\mathrm{P}$-value refers to the results of one-sample Wilcoxon signed-rank t-tests with $\mathrm{H}_{0}$ : median=0. 
Table 4 Differences between migrators, people with prior online gambling involvement and people who exclusively gamble at land-based venues.

\begin{tabular}{|c|c|c|c|c|c|c|}
\hline & Migrators & $\begin{array}{l}\text { People with } \\
\text { prior online } \\
\text { gambling } \\
\text { involvement }\end{array}$ & $\begin{array}{r}\text { People who } \\
\text { exclusively } \\
\text { gambled at } \\
\text { land-based } \\
\text { venues }\end{array}$ & $x^{2}$ & P-value & $\begin{array}{r}\text { Partial } \\
\eta^{2}\end{array}$ \\
\hline PGSI & $267.03 \mathrm{a}$ & $260.46_{a}$ & $159.16_{b}$ & 74.32 & $<0.001$ & 0.159 \\
\hline Age & 182.13 & $192.90_{\mathrm{a}}$ & $234.56_{b}$ & 13.54 & 0.001 & 0.032 \\
\hline Household income & $161.46_{a}$ & 204.42 & $228.71_{b}$ & 10.61 & 0.005 & 0.025 \\
\hline Change in alcohol use & 170.70 & 148.13 & 158.96 & 2.10 & 0.350 & 0.007 \\
\hline Change in tobacco use & 115.94 & 101.54 & 103.37 & 1.06 & 0.588 & 0.005 \\
\hline Change in cannabis use & 88.94 & 90.30 & 88.44 & 0.06 & 0.970 & 0.000 \\
\hline $\begin{array}{l}\text { Change in video } \\
\text { gaming }\end{array}$ & 148.11 & $163.70_{\mathrm{a}}$ & $135.20_{\mathrm{b}}$ & 7.67 & 0.022 & 0.025 \\
\hline $\begin{array}{l}\text { Change in pornography } \\
\text { use }\end{array}$ & $159.00_{\mathrm{a}}$ & 134.11 & $117.33 \mathrm{~b}$ & 8.28 & 0.016 & 0.032 \\
\hline $\begin{array}{l}\text { Change in social casino } \\
\text { gaming }\end{array}$ & $170.22_{\mathrm{a}}$ & $134.02 \mathrm{~b}$ & $115.16 \mathrm{~b}$ & 12.19 & 0.002 & 0.047 \\
\hline
\end{tabular}

Note. Mean ranks with different subscripts differed significantly at $\alpha=0.05$ using Dunn's test for pairwise comparisons with Bonferroni correction for familywise error rate. 